\title{
Prognostic factors including lymphovascular invasion on survival for resected non-small cell lung cancer
}

\author{
Lawrence Okiror, MBChB, MRCS, Leanne Harling, BSc, MBBS, MRCS, PhD, \\ Levon Toufektzian, MD, MSc, Juliet King, DM, BM, FRCS, CTh, Tom Routledge, MA, FRCS, CTh, \\ Karen Harrison-Phipps, FRCS, CTh, John Pilling, FRCS, CTh, Lukacs Veres, MD, Ruchi Lal, MSc, and \\ Andrea Bille, MD, PhD, FRCS
}

\section{ABSTRACT}

Objectives: The aim of this study was to report on the influence of tumor lymphovascular invasion on overall survival and in patients with resected non-small cell lung cancer and identify prognostic factors for survival.

Methods: This is a retrospective observational study of a consecutive series of patients who had surgical resection of non-small cell lung cancer in a single institution. The study covers a 3 -year period. Overall survival was estimated by Kaplan-Meier method and multivariate Cox regression analysis was used to evaluate the relationship of lymphovascular invasion and other clinicopathologic variables. A multivariate regression was used to assess the relationship between tumor lymphovascular invasion and other clinical and pathologic characteristics.

Results: A total of 524 patients were identified and included in the study. Two hundred twenty-five patients $(43 \%)$ had tumors with lymphovascular invasion. Patients with tumor lymphovascular invasion had a lower overall survival $(P<.0001)$. Tumor lymphovascular invasion was independently associated with visceral pleural involvement $(P<.0001)$. In a multivariable model, lymphovascular invasion (hazard ratio [HR], 2.58; 95\% confidence interval [CI], 1.63$4.09 ; P<.0001$ ), parietal pleural invasion (HR, 45.4; 95\% CI, 2.08-990; $P=.015)$, advanced age (HR, $1.028 ; 95 \% \mathrm{CI}, 1.009-1.048 ; P=.004)$, and N2 lymph node involvement (HR, 1.837; 95\% CI, 1.257-2.690; $P=.002$ ) were independent prognostic factors for lower overall survival.

Conclusions: Lymphovascular invasion is associated with a worse overall survival in patients with resected non-small cell lung cancer regardless of tumor stage. Parietal pleural involvement, N2 nodal disease, and advanced age independently predict poor overall survival. (J Thorac Cardiovasc Surg 2018;156:785-93)

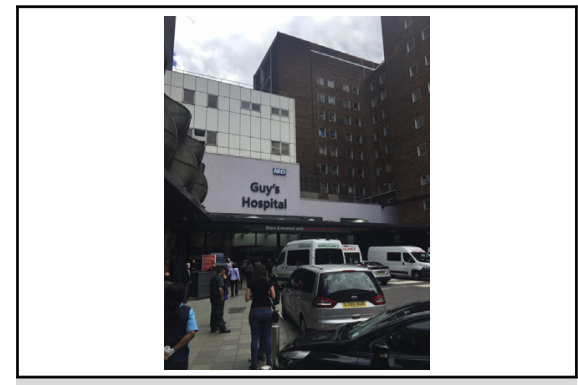

Guy's Hospital.

\section{Central Message}

Tumor lymphovascular invasion is associated with a worse overall survival in patients with resected NSCLC.

\section{Perspective}

This retrospective observational study of 524 patients with resected NSCLC shows that tumor lymphovascular invasion significantly influences overall survival. We found an association between tumor lymphovascular invasion and visceral pleural involvement as well as tumor size. Lymphovascular invasion may be a marker of subclinical tumor spread.

See Editorial Commentary page 794
Surgical resection with lymph node dissection is the mainstay of treatment of early stage (T1, T2, or T3; N0 or N1) non-small cell lung cancer (NSCLC). Pathologic stage is the most important prognostic factor for survival following resection and is the basis of guideline recommendations for adjuvant therapies. Adjuvant chemotherapy is offered to patients with pathologically confirmed lymph node

\footnotetext{
From the Department of Thoracic Surgery, Guy's and St Thomas' Hospitals, London, United Kingdom.

Received for publication May 16, 2017; revisions received Feb 6, 2018; accepted for publication Feb 15, 2018; available ahead of print May 10, 2018.

Address for reprints: Andrea Bille, MD, PhD, FRCS, Department of Thoracic Surgery, 6th Fl, Borough Wing, Guy's Hospital, Great Maze Pond, London SE1 9RT, United Kingdom (E-mail: andrea.bille@gstt.nhs.uk). $0022-5223 / \$ 36.00$

Copyright (C) 2018 by The American Association for Thoracic Surgery https://doi.org/10.1016/j.jtcvs.2018.02.108
}

involvement on the basis of evidence of survival benefit from randomized trial data. ${ }^{1-4}$ Analysis of data from a subgroup of patients with node-negative NSCLC suggests that there may be a survival benefit for adjuvant chemotherapy in larger tumors. ${ }^{5}$ The role of adjuvant radiotherapy after resection of NSCLC is less well defined but is generally recommended for patients with incompletely removed involved mediastinal lymph nodes and positive resection margins. ${ }^{6}$ Survival for lung cancer, especially in the

$\square$ Scanning this QR code will take
you to a supplemental video for
the article.




\section{Abbreviations and Acronyms \\ LVI = lymphovascular invasion \\ NSCLC $=$ non-small cell lung cancer \\ OS $=$ overall survival}

presence of lymph node involvement, remains poor. Better understanding of a number of tumor biological factors may help better stratify patients beyond current staging and identify patients at risk of early recurrence who may require adjuvant therapies to mitigate this risk.

Lymphovascular invasion (LVI) has been shown to independently predict early recurrence following resection of NSCLC. $^{7-12}$ Some authors have proposed that in the presence of lymphovascular invasion adjuvant therapies should be considered even in node-negative disease, as is the case for a number of gynecologic and head and neck epithelial malignancies. ${ }^{6,13-16}$ The purpose of this study was to report on the influence of tumor lymphovascular invasion on overall survival (OS) in patients with NSCLC who have undergone resection and to identify prognostic factors for overall survival.

\section{MATERIALS AND METHODS}

This was a retrospective observational study of a consecutive series of patients with NSCLC who underwent surgical resection for stage T1 through T3 N0 through N2 M0 disease at a single institution over a 3year period. All staging was according to the seventh edition of the joint American Joint Committee on Cancer and the International Union for Cancer Control. Patients were excluded if they had carcinoid tumors, if they had a prior history of lung cancer, or if they received preoperative chemotherapy and/or radiotherapy. Ethical approval for this study was obtained from the institutional review board. LVI was defined by detecting the tumor emboli within vascular channels lined by single layer of endothelial cells in the resected primary tumor following staining with hematoxylin and eosin. Results were reported by 2 dedicated thoracic histopathologists.

\section{Patients}

All patients were discussed at dedicated lung cancer multidisciplinary team meetings before referral for surgery. A standard preoperative workup was performed for each patient according to established guidelines. ${ }^{17}$ Individual patient data were obtained from a prospective surgical database and patient case notes. Data on mortality were obtained from a national register of deaths.

\section{Statistical Analysis}

Continuous data are reported as median and range, and categorical data are reported as count and percentage. Survival was measured from the date of surgery. Survival and prognostic factors were analyzed by the KaplanMeier method. Univariate analysis of data was performed using $\chi^{2}$ test, $\log$ rank test, Fisher exact test, unpaired $t$ test, and analysis of variance, where appropriate. Factors that significantly influenced survival in univariate analysis (at $P<.10$ ) were tested for their independent role in multivariate analysis using the Cox proportional hazards model. The stepwise backward procedure based on the likelihood ratio was used to assess the significance of covariates included in the model. Colinearity was assessed using a correlation matrix of coefficients in the Cox regression model. Any variables with coefficient $>0.75$ or $<-0.75$ were considered colinear. No colinearity of variables was observed in the final multivariable model. Hazard ratios (HRs) and 95\% confidence intervals (CIs) were calculated. All analyses were conducted using SPSS software version 18 (IBM-SPSS Inc, Armonk, NY).

\section{RESULTS}

\section{Patient Characteristics}

Between April 2011 and March 2013, a total of 524 patients had lung resection for pathologic stage T1, T2, or T3 N0, N1, or N2 M0 NSCLC at our institution and are included in this study. The median age was 73 years (range, $37-95$ years) and $240(46 \%)$ were men. Baseline characteristics of the study population are summarized in Table 1.

\section{Operative Procedures and Staging}

The majority of patients had a lobectomy and lymphadenectomy as the surgical procedure. Bilobectomy was performed in $28(5 \%)$. Pneumonectomy was performed in 31 patients $(6 \%)$ (Table 1). Stage distribution is summarized in Table 1. Three quarters of operations were performed

TABLE 1. Baseline characteristics of the study population

\begin{tabular}{lc}
\hline \multicolumn{1}{c}{ Parameter } & Result \\
\hline Age, y & $73(37-95)$ \\
Gender, male & $240(46)$ \\
Type of operation & \\
Lobectomy & $461(78)$ \\
Sleeve lobectomy & $50(10)$ \\
Bilobectomy & $18(3)$ \\
Pneumonectomy & $31(6)$ \\
Segmentectomy & $14(3)$ \\
Surgical approach & \\
Thoracotomy & $399(76)$ \\
Video-assisted thoracoscopic surgery & $125(24)$ \\
Histology & \\
Adenocarcinoma & $301(57)$ \\
Squamous cell carcinoma & $195(37)$ \\
Large cell neuroendocrine carcinoma & $16(3)$ \\
Sarcomatoid & $10(1.9)$ \\
Small cell & $2(0.38)$ \\
pTNM stage & \\
In situ & $4(0.76)$ \\
IA & $138(26)$ \\
IB & $141(27)$ \\
IIA & $81(15)$ \\
IIB & $59(11)$ \\
IIIA & $100(19)$ \\
IIIB & $1(0.19)$ \\
IV & $0(0)$ \\
Lymphovascular invasion & \\
Positive & $225(43)$ \\
Negative & $299(57)$ \\
\hline V &
\end{tabular}

Values are presented as median (range) or $\mathrm{n}(\%)$. 
TABLE 2. Table comparing baseline characteristics of patients with lymphovascular invasion (LVI) to those without LVI

\begin{tabular}{|c|c|c|c|}
\hline Characteristic & Patients with tumor LVI $(n=225)$ & Patients without tumor LVI $(n=299)$ & $P$ value \\
\hline Age, y & $73(57,67,73,79,86)$ & $73(58,68,73,79,85)$ & .844 \\
\hline Male sex & $93(41)$ & 147 (49) & .075 \\
\hline Tumor size & $38.9 \pm 20.6$ & $34.7 \pm 23.2$ & .033 \\
\hline \multicolumn{4}{|l|}{ Smoking status } \\
\hline Nonsmoker & 3 & 6 & .743 \\
\hline Exsmoker & 73 & 132 & .092 \\
\hline Current smoker & 32 & 34 & .058 \\
\hline Unknown & 117 & 127 & .030 \\
\hline \multicolumn{4}{|l|}{ Type of operation } \\
\hline Lobectomy & $192(85)$ & $259(87)$ & .673 \\
\hline Bilobectomy & $12(5)$ & $16(5)$ & .993 \\
\hline Pneumonectomy & $14(6)$ & $17(6)$ & .797 \\
\hline Segmentectomy & $7(3)$ & $7(2)$ & .588 \\
\hline \multicolumn{4}{|l|}{ Pleural involvement } \\
\hline Visceral & $128(57)$ & $95(32)$ & $<.0001$ \\
\hline Parietal & $22(10)$ & $17(6)$ & .077 \\
\hline \multicolumn{4}{|l|}{ Surgical approach } \\
\hline Thoracotomy & $179(80)$ & $220(74)$ & .112 \\
\hline Video-assisted thoracoscopic surgery & $46(20)$ & $79(26)$ & .112 \\
\hline \multicolumn{4}{|l|}{ Histology } \\
\hline Adenocarcinoma & $130(58)$ & $177(59)$ & .744 \\
\hline Squamous cell carcinoma & $87(39)$ & $112(38)$ & .778 \\
\hline Large cell neuroendocrine carcinoma & 4 & 1 & .093 \\
\hline Small cell & 1 & 1 & .840 \\
\hline Other* & 3 & 7 & .404 \\
\hline \multicolumn{4}{|l|}{ pTNM stage } \\
\hline In situ & $0(0)$ & $4(1)$ & .082 \\
\hline IA & $34(15)$ & $104(35)$ & $<.0001$ \\
\hline IB & $58(26)$ & $83(28)$ & .613 \\
\hline IIA & $40(18)$ & $41(14)$ & .203 \\
\hline IIB & $26(12)$ & $33(11)$ & .852 \\
\hline IIIA & $66(29)$ & $34(11)$ & $<.0001$ \\
\hline IIIB & $1(0.44)$ & $0(0)$ & .24 \\
\hline IV & $0(0)$ & $0(0)$ & - \\
\hline
\end{tabular}

Values are presented as median (5th, 25th, 50th, 75th, and 95th percentiles), mean \pm standard deviation, or $\mathrm{n}(\%)$. *Sarcomatoid lung cancer or small cell lung cancer

by thoracotomy $(\mathrm{n}=399 ; 76 \%$ vs video-assisted thoracoscopic surgery $\mathrm{n}=125 ; 24 \%)$.

\section{Lymphovascular Invasion and Histologic Subtype}

The histologic distribution of patients with tumor LVI is summarized in Table 2. There was no correlation of tumor histologic subtype and LVI ( $\chi^{2}$ for adenocarcinoma vs all other tumors and LVI was $0.1066 ; P=.744)$.

\section{Lymphovascular Invasion and Pleural Involvement}

The presence of LVI was significantly associated with visceral pleural involvement with tumor $(P<.0001)$. LVI was not significantly associated with parietal pleural involvement $(P=.077)$ (Table 2).
OS

The OS of the study group was $86.5 \%$ (95\% CI, 83.2$89.1)$ at 1 year, $73.9 \%(95 \% \mathrm{CI}, 69.9-77.4)$ at 2 years, $65.9 \%(95 \% \mathrm{CI}, 61.6-69.8)$ at 3 years, and $62.6 \%(95 \%$ CI, 58.0-66.8) at 4 years with a median follow-up of 36.5 months (range, 3-55 months). As expected, OS was worse with increasing $\mathrm{T}$ stage, lymph node involvement (N2 indicates worst OS, N0 indicates best OS), and TNM stage (stage III indicates worst OS and stage IA indicates best OS) (Figures 1 and 2).

The presence of tumor LVI was associated with a worse overall survival. Patients with no LVI demonstrated $89.3 \%$ (95\% CI, 85.2-92.3), 82.6\% (95\% CI, 77.8-86.5), 75.3\% (95\% CI, 69.9-79.8), and 72.8\% (95\% CI, 67.1-77.6) OS at $1,2,3$, and 4 years, respectively. Patients with LVI 

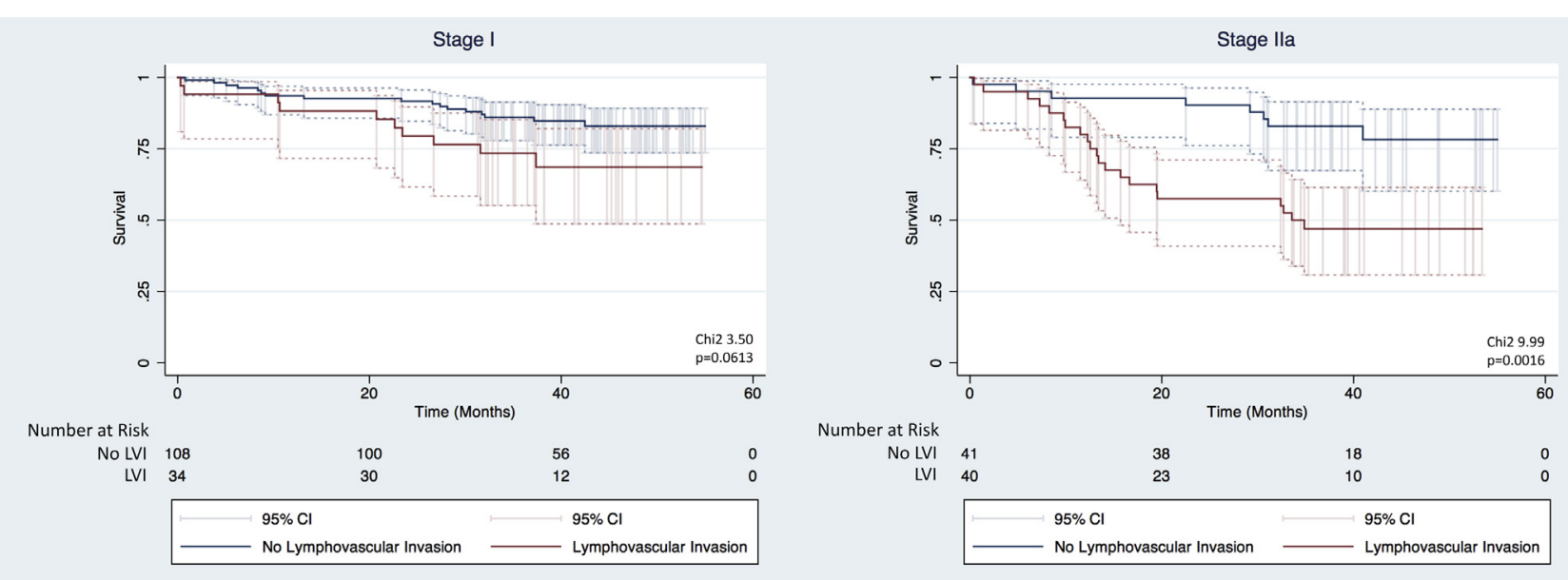

FIGURE 1. Kaplan-Meier curve comparing overall survival of patients with tumor lymphovascular invasion (LVI) to those without in stages I and IIA. CI, Confidence interval.

demonstrated significantly worse OS $\left(\chi^{2}=29.51\right.$; $P<.0001)$, corresponding to $82.7 \%$ (95\% CI, 77.1-87.0), $62.2 \%$ (95\% CI, 55.5-68.2), 53.3\% (95\% CI, 46.5-59.6), and $48.7 \%(95 \% \mathrm{CI}, 41.0-55.9)$ at $1,2,3$, and 4 years, respectively Figure 3.

The OS of patients with LVI was significantly different only for patients with stage IIA disease (Figures 1 and 2).

\section{Prognostic Factors for OS}

Univariate and multivariate Cox regression models were fitted to test for individual factors contributing to OS. The individual factors entered into the univariate analysis with their corresponding $P$ values are summarized in Table 3. Each variable was assessed for violation of proportionality assumption through Schoenfeld residuals. No significant violation of this assumption was identified (Table 3).
Multivariate Cox regression showed a significant interaction between the variables of advanced age and parietal pleural invasion; LVI and visceral pleural invasion; and LVI and parietal pleural invasion. Confirmation that the proportional hazards assumption was met was assessed through Schoenfeld residuals. Results for each independent regression variable are shown in Table 3. Results of a global test of proportional hazards assumption for the adjusted multivariable model revealed $\chi^{2}=18.30$ with $P>\chi^{2}=0.436$ suggesting no violation of the proportional hazards assumption (Table 4).

A Cox proportional hazards model was used to test the variables in Table 3 for their significance in a multivariate model. The fully adjusted model taking into account interactions is shown in Table 4. Of these only age $(\geq 70$ years $)(P=.004), \mathrm{N} 2$ nodal involvement $(P=.002)$, LVI $(P<.0001)$, and parietal pleural
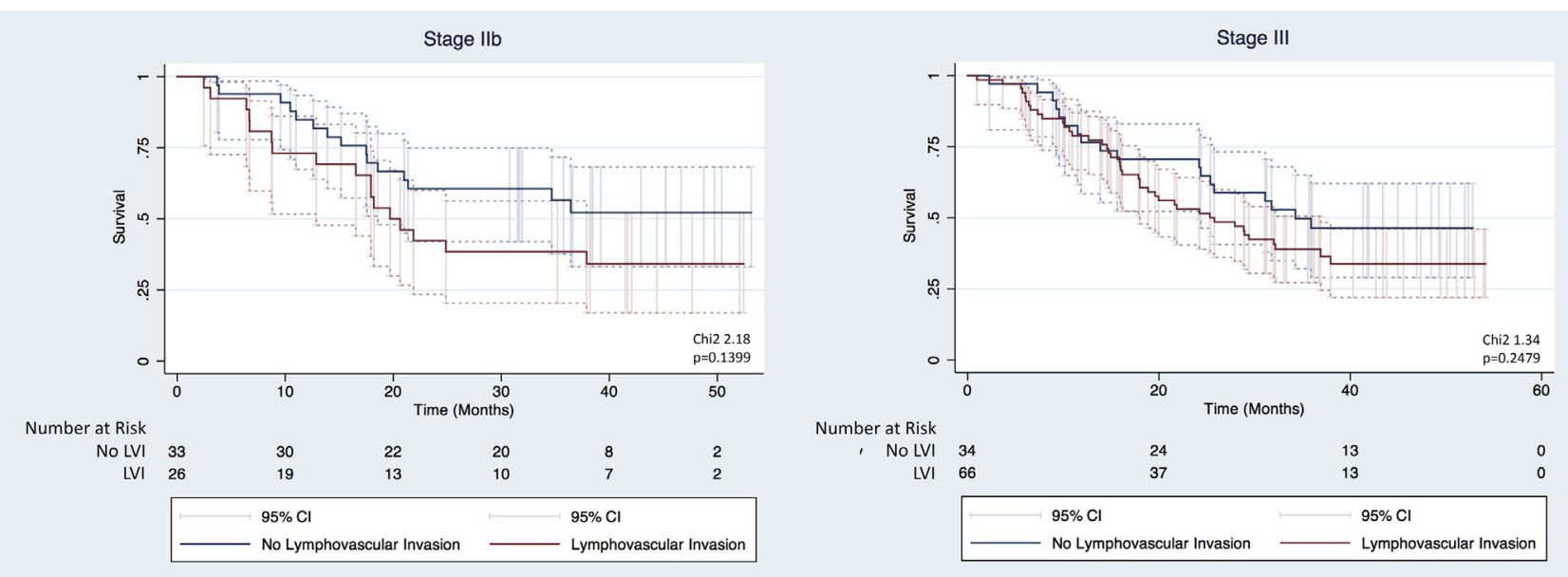

FIGURE 2. Kaplan-Meier curve comparing overall survival of patients with tumor lymphovascular invasion (LVI) to those without in stages IIB and III. CI, Confidence interval. 


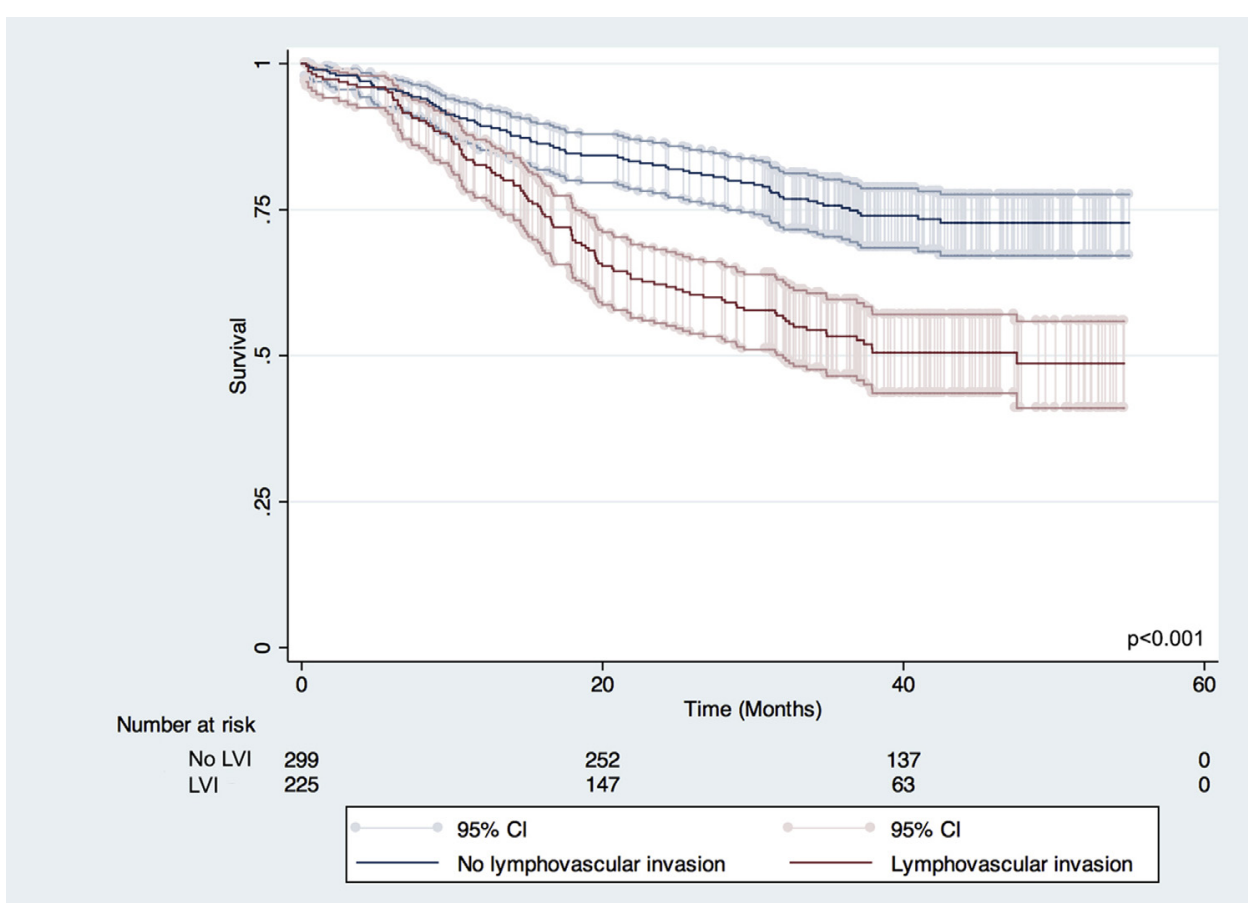

FIGURE 3. Kaplan-Meier curve comparing overall survival of patients with tumor lymphovascular invasion (LVI) to those without in stages I and IIA. CI, Confidence interval.

involvement $(P=.015)$ were statistically significant independent variables (Table 4).

\section{DISCUSSION}

Our results show that tumor LVI is associated with a worse OS in patients with resected NSCLC. In addition there was an association between tumor LVI and lymph node involvement as well as visceral pleural involvement.

Surgical resection remains the treatment of choice for patients with early stage (I and II as well as selected stage IIIA) NSCLC. There remains a high rate of relapse in these patients with 5-year survival of resected lung cancer varying between $73 \%$ for stage IA NSCLC and $24 \%$ for stage IIIA $^{18}$ This pattern is borne out in our data showing near identical overall survival data especially in patients with no LVI, albeit at 4 years.

The role of platinum-based adjuvant chemotherapy for NSCLC was first defined by the International Adjuvant Lung Cancer Trial and subsequently confirmed by the Lung Adjuvant Cisplatin Evaluation (LACE) meta-analysis of 5 adjuvant chemotherapy trials. ${ }^{2,4}$ Survival benefit from adjuvant chemotherapy remains limited, ranging from $5 \%$ to $8 \%$ at 5 years. ${ }^{4}$ There is, therefore, a need to define novel variables to better stratify patients likely to benefit from adjuvant treatment. This will not only help to inform prognosis, but also the need for adjuvant therapies. Adjuvant chemotherapy is offered to patients with involvement of intrathoracic lymph nodes as well as patients with no lymph node involvement but with larger tumors. It may be that the real value of LVI as a potential marker of tumor metastatic potential by local lymphatic invasion is in the group of patients with no nodal involvement (ie, stage I lung cancer patients). Whilst our results showed the OS of patients with stage I lung cancer and LVI was not statistically significantly worse than those without $(P=.06)$ (Figure 1$)$ this may be an area of future study and may be of value in evaluation of adjuvant therapies.

The presence of tumor LVI has been shown to confer a poor prognosis in multiple studies to date. ${ }^{6-12}$ (Table 5). Our results show the overall survival of patients with tumors having LVI was worse in the whole cohort and in the various stages (stage I-IIIA). This effect is more marked in patients with early stage NSCLC (stage I and IIA) than in locally advanced disease (stage IIB and IIIA). It is possible that in patients with smaller tumors, the presence of LVI is an early sign of subclinical tumor spread and therefore increases the risk of recurrence (Video 1). Tumor microscopic metastases begin with local invasion of surrounding tissue stroma and proceeds to penetrate lymphatic or blood vessel. ${ }^{36}$ Micrometastases then result from the clonal growth of tumor subpopulations with highly metastatic potential that then invade locoregional lymph nodes. ${ }^{37}$ This may explain the correlation of tumor LVI and presence of lymph node spread that we found in this study and has 
TABLE 3. Individual variables entered into the univariate model to test for their significance with corresponding $P$ values*

\begin{tabular}{|c|c|c|c|c|}
\hline \multirow[b]{3}{*}{ Variable } & \multicolumn{3}{|c|}{ Cox regression model } & \multirow{3}{*}{$\begin{array}{c}\text { Proportional hazards testing based } \\
\text { on Schoenfeld residuals } \\
P \text { value }\end{array}$} \\
\hline & \multicolumn{3}{|c|}{$\mathbf{9 5} \%$ confidence } & \\
\hline & Hazard ratio & interval & $P$ value & \\
\hline Gender & 0.854 & $0.64-1.14$ & .286 & .7174 \\
\hline Access (video-assisted thoracoscopic surgery vs thoracotomy) & 0.749 & $0.52-1.08$ & .119 & .9396 \\
\hline Lymphovascular invasion & 2.16 & $1.62-2.90$ & $<.0001$ & .7331 \\
\hline Visceral pleural invasion & 1.87 & $1.40-2.49$ & $<.0001$ & .0656 \\
\hline Parietal pleural involvement & 3.19 & $2.13-4.79$ & $<.0001$ & .8708 \\
\hline \multicolumn{5}{|l|}{ T category } \\
\hline $1 \mathrm{a}$ & Base & Base & Base & Base \\
\hline $1 b$ & 1.087 & $0.59-2.02$ & .791 & .2445 \\
\hline $2 \mathrm{a}$ & 1.480 & $0.89-2.45$ & .128 & .8539 \\
\hline $2 b$ & 2.706 & $1.54-4.77$ & .001 & .7253 \\
\hline $3 a$ & 3.211 & $1.90-5.42$ & $<.0001$ & .7272 \\
\hline $3 b$ & 4.133 & $1.88-9.09$ & $<.0001$ & .0505 \\
\hline Global test & - & - & - & .2068 \\
\hline \multicolumn{5}{|l|}{$\mathrm{N}$ category } \\
\hline 1 & Base & Base & Base & Base \\
\hline 2 & 1.483 & $0.99-2.22$ & .055 & .6055 \\
\hline 3 & 2.178 & $1.53-3.09$ & $<.0001$ & .4456 \\
\hline Global test & - & - & - & .7047 \\
\hline \multicolumn{5}{|l|}{ Extent of resection } \\
\hline Lobectomy & Base & Base & Base & Base \\
\hline Bilobectomy & 0.766 & $0.38-1.56$ & .463 & .6462 \\
\hline Sementectomy & 1.471 & $0.69-3.14$ & .318 & .4342 \\
\hline Pneumonectomy & 1.428 & $0.84-2.43$ & .188 & .4833 \\
\hline Global test & - & - & - & .7562 \\
\hline \multicolumn{5}{|l|}{ Histology } \\
\hline Large cell neuroendocrine & Base & Base & Base & Base \\
\hline Adenocarcinoma & 0.765 & $0.19-3.10$ & .708 & .8682 \\
\hline Squamous cell & 1.013 & $0.25-4.12$ & .985 & .9023 \\
\hline Small cell & 1.854 & $0.17-20.5$ & .614 & .1372 \\
\hline Other & 2.511 & $0.52-12.1$ & .251 & .6513 \\
\hline Global test & - & & - & .1834 \\
\hline \multicolumn{5}{|l|}{ TNM stage } \\
\hline IA & Base & Base & Base & Base \\
\hline IB & 1.512 & $0.93-2.47$ & .099 & .3457 \\
\hline IIA & 2.059 & $1.22-3.48$ & .007 & .5919 \\
\hline IIB & 3.667 & $2.20-6.13$ & $<.0001$ & .5837 \\
\hline IIIA & 4.079 & $2.59-6.43$ & $<.0001$ & .7914 \\
\hline Global test & - & - & - & .6339 \\
\hline Skip lesions $\uparrow$ & 0.77 & $0.40-1.51$ & .452 & .1552 \\
\hline Age $\geq 70 y$ & 1.015 & $1.00-1.03$ & .094 & - \\
\hline Tumor size, $\geq \mathrm{mm}$ & 1.014 & $1.01-1.10$ & $<.0001$ & - \\
\hline
\end{tabular}

*Univariate analysis significant at $P=.1$. $\dagger$ Involvement of mediastinal lymph nodes (N2, N3) without N1 nodal involvement.

previously been reported. ${ }^{6,37,38}$ Tumor LVI has been noted to correlate with the development of distant metastatic disease on follow-up. ${ }^{6}$ Again, this probably relates to the metastatic potential of these tumors demonstrated by local lymphatic and vascular invasion with subsequent dissemination of tumor cells via the respective vessels. We did 
TABLE 4. Multivariable cox regression model*

\begin{tabular}{|c|c|c|c|c|}
\hline Variable & Hazard ratio & $P$ value & $\mathbf{9 5} \%$ confidence interval & $\begin{array}{c}\begin{array}{c}\text { Test of proportional hazards } \\
\text { based on Schoenfeld residuals }\end{array} \\
P \text { value }\end{array}$ \\
\hline Age & 1.03 & .004 & $1.01-1.05$ & .410 \\
\hline \multicolumn{5}{|l|}{ T Stage (base 1a) } \\
\hline $1 b$ & 0.764 & .421 & $0.397-1.47$ & .310 \\
\hline $2 \mathrm{a}$ & 0.910 & .749 & $0.511-1.62$ & .819 \\
\hline $2 b$ & 1.78 & .070 & $0.954-3.33$ & .378 \\
\hline $3 a$ & 1.35 & .383 & $0.689-2.64$ & .377 \\
\hline $3 b$ & 1.88 & .144 & $0.805-4.40$ & .053 \\
\hline \multicolumn{5}{|l|}{ N Stage (base N0) } \\
\hline N1 & 1.26 & .289 & $0.819-1.95$ & .993 \\
\hline $\mathrm{N} 2$ & 1.83 & .002 & $1.26-2.69$ & .885 \\
\hline Lymphovascular invasion & 2.58 & $<.001$ & $1.63-4.09$ & .350 \\
\hline Visceral pleural invasion & 0.953 & .833 & $0.607-1.50$ & .758 \\
\hline Parietal pleural invasion & 45.4 & .015 & $2.08-990.5$ & .330 \\
\hline \multicolumn{5}{|l|}{ Histology (base large cell neuroendocrine) } \\
\hline Adenocarcinoma & 0.891 & .875 & $0.214-3.72$ & .924 \\
\hline Squamous cell & 1.07 & .928 & $0.255-4.48$ & .794 \\
\hline Small cell & 6.07 & .149 & $0.523-70.4$ & .098 \\
\hline Other & 3.10 & .173 & $0.608-15.9$ & .821 \\
\hline \multicolumn{5}{|l|}{ Interaction variables } \\
\hline Lymphovascular invasion and parietal pleural invasion & 1.73 & .235 & $0.701-4.27$ & .231 \\
\hline Lymphovascular invasion and visceral pleural invasion & 1.72 & .102 & $0.898-3.29$ & .127 \\
\hline Parietal pleural invasion and age & 0.954 & .034 & $0.913-0.996$ & .403 \\
\hline
\end{tabular}

*(Breslow method for ties): Overall model (with hazard ratios) - Number of subjects $=519 ; 187$ failures. Likelihood ratio $\chi^{2}=101.15 ; d f=19 ;$ probability $>\chi^{2}<.00001$.

not have data on disease recurrence in our cohort of patients owing to a large majority of patients in our institution coming from various referral centers where their subsequent follow-up is done.

Our data did not show tumor subtype (adenocarcinoma vs squamous cell carcinoma) to predict the presence of LVI. Previous reports have noted an association between LVI and death or developing distant metastatic disease in patients with adenocarcinoma histology but not squamous cell carcinoma. ${ }^{6}$ No explanation was offered for this correlation by the authors.

The proportion of patients with tumor LVI in our study is relatively high $(43 \%)$. However, in their meta-analysis of studies reporting patients with tumor LVI, Wang and colleagues ${ }^{37}$ found a median of $32 \%$ of tumor samples were reported to contain tumor LVI with a range of $2.8 \%$ to $70.9 \%$. It is not clear why there is such wide variability in tumor LVI. However, it has been noted that whilst hematoxylin and eosin staining is the most common means of reporting LVI in tumors, it can have a false negative rate of $13.85 \%$ to $18 \%$ and a falsepositive rate of $4 \%$ to $11.1 \% .^{39,40}$ The use of the monoclonal antibody D2-40, a marker of lymphatic endothelium to identify tumor emboli in lymph vessels may improve accuracy in identifying LVI. ${ }^{41}$ However, there are concerns about the immunoreactivity of D2-40 to the basal cell layer of the squamous epithelium, stromal myofibroblasts, mesothelial cells, and lung cancer cells that may confound results. ${ }^{19,42}$

There are a number of limitations of this study. Firstly, it contains data from a single institution, which may influence applicability to other patient populations. Secondly, the period of follow-up is limited, which may influence the ability to detect variables significantly influencing survival due to small number of events that occur during the follow-up period, especially in the multivariate model. Thirdly, we have not included in the multivariate model data on lung function, patient comorbidity, and postoperative adjuvant therapy, factors that are known to influence survival in surgical patients undergoing lung resection. These data were incomplete and hence unreliable, owing to patients in our institution being followed-up by the referring physicians in various regional hospitals and we do not have access to those records. 
TABLE 5. Summary of studies reporting on the impact of tumor lymphovascular invasion (LVI) on overall survival (OS) in resected non-small cell lung cancer (NSCLC) over the past decade

\begin{tabular}{|c|c|c|c|c|c|c|c|c|}
\hline \multirow[b]{2}{*}{ First author } & \multirow[b]{2}{*}{ Year } & \multirow[b]{2}{*}{ Country } & \multirow[b]{2}{*}{$\mathbf{n}$} & \multirow[b]{2}{*}{ LVI positive } & \multirow[b]{2}{*}{ Stage } & \multirow[b]{2}{*}{ Histology } & \multicolumn{2}{|c|}{ OS } \\
\hline & & & & & & & $\begin{array}{c}\text { Univariate } \\
\text { analysis }\end{array}$ & $\begin{array}{c}\text { Multivariate } \\
\text { analysis }\end{array}$ \\
\hline Moon and colleagues $^{19}$ & 2017 & Korea & 271 & 71 & IA & NSCLC & N/A & NS \\
\hline Kinoshita and colleagues $^{12}$ & 2015 & Japan & 629 & 85 & I-III & NSCLC & NA & $S$ \\
\hline Al-Alao and colleagues ${ }^{20}$ & 2014 & Ireland & 457 & 25 & I-II & NSCLC & NS & NA \\
\hline Tao and colleagues ${ }^{21}$ & 2013 & Japan & 142 & 22 & I-II & NSCLC & $S$ & $S$ \\
\hline Yanagawa and colleagues ${ }^{9}$ & 2013 & Japan & 433 & 41 & I-III & NSCLC & $S$ & $S$ \\
\hline Higgins and colleagues ${ }^{6}$ & 2012 & USA & 1559 & 352 & I-III & NSCLC & S & $S$ \\
\hline Maeda and colleagues ${ }^{22}$ & 2012 & Japan & 1070 & 233 & IA & NSCLC & $S$ & S \\
\hline Hanagiri and colleagues ${ }^{8}$ & 2011 & Japan & 226 & 70 & I & NSCLC & S & NS \\
\hline Araki and colleagues ${ }^{23}$ & 2011 & Japan & 26 & 7 & IB & NSCLC & NS & $\mathrm{N} / \mathrm{A}$ \\
\hline Funai and colleagues ${ }^{24}$ & 2011 & Japan & 229 & 32 & IA & NSCLC & S & $S$ \\
\hline Sakai and colleagues ${ }^{25}$ & 2011 & Japan & 548 & 265 & I-IV & NSCLC & N/A & S \\
\hline Harada and colleagues ${ }^{26}$ & 2011 & Japan & 610 & 225 & I & NSCLC & S & S \\
\hline Maeda and colleagues ${ }^{27}$ & 2011 & Japan & 434 & 134 & IB & NSCLC & NS & NS \\
\hline Shimada and colleagues ${ }^{28}$ & 2010 & Japan & 1000 & 244 & I-IV & NSCLC & $S$ & N/A \\
\hline Kawachi and colleagues $^{29}$ & 2009 & Japan & 226 & 13 & I & NSCLC & N/A & S \\
\hline Kawachi and colleagues ${ }^{30}$ & 2009 & Japan & 376 & 90 & I-IV & NSCLC & N/A & S \\
\hline Sun and colleagues ${ }^{31}$ & 2009 & China & 82 & 46 & I-III & NSCLC & S & NS \\
\hline Hashizume and colleagues $^{32}$ & 2009 & Japan & 221 & 92 & IA & NSCLC & $S$ & $S$ \\
\hline Higashiyama and colleagues ${ }^{33}$ & 2009 & Italy & 679 & 327 & I-IV & NSCLC & S & S \\
\hline Bodendorf and colleagues ${ }^{34}$ & 2009 & Germany & 112 & 41 & IIB-III & NSCLC & S & N/A \\
\hline Matsuguma and colleagues ${ }^{35}$ & 2008 & Japan & 455 & 69 & I & NSCLC & N/A & NS \\
\hline
\end{tabular}

LVI, Lymphovascular invasion; $O S$, overall survival; $N / A$, not available or not applicable; $N S$, no significant relationship between LVI and survival; $S$, statistically significant relationship between LVI and survival.

\section{CONCLUSIONS}

We believe that this study, which had a large number of patients, carries an important message: Patients with tumor LVI have a lower overall survival compared with those with no LVI in resected NSCLC. We believe that the presence of

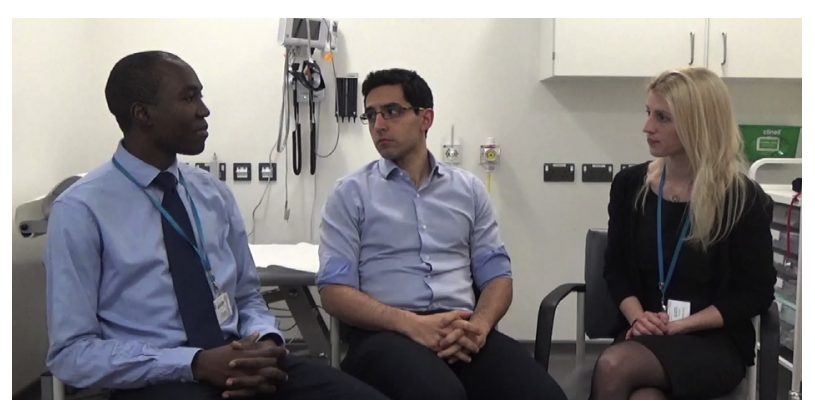

VIDEO 1. Drs Bille, Okiror, and Harling discuss the key findings of this articles with particular focus on the prognostic implications of lymphovascular invasion on overall and stage-specific survival. Video available at: https://www.jtcvs.org/article/S0022-5223(18)30935-8/fulltext. tumor LVI could be tested as a variable for offering patients with resected NSCLC adjuvant therapies.

\section{Conflicts of Interest Statement}

Authors have nothing to disclose with regard to commercial support.

\section{References}

1. Douillard JY, Rosell R, De Lena M, Carpagnano F, Ramlau R, GonzálesLarriba JL, et al. Adjuvant vinorelbine plus cisplatin versus observation in patients with completely resected stage IB-IIIA non-small-cell lung cancer (Adjuvant Navelbine International Trialist Association [ANITA]): a randomised controlled trial. Lancet Oncol. 2006;7:719-27.

2. Arriagada R, Bergma B, Dunant A, Le Chevalier T, Pignon JP, Vansteenkiste J, et al. Cisplatin-based adjuvant chemotherapy in patients with completely resected non-small-cell lung cancer. N Engl J Med. 2004;350:351-60.

3. Winton T, Livingston R, Johnson D, Rigas J, Johnston M, Butts C, et al. Vinorelbine plus cisplatin vs. observation in resected non-small-cell lung cancer. $N$ Engl J Med. 2005;352:2589-97.

4. Pignon JP, Tribodet H, Scagliotti GV, Douillard JY, Shepherd FA, Stephens RJ, et al. Lung adjuvant cisplatin evaluation: a pooled analysis by the LACE Collaborative Group. J Clin Oncol. 2008;26:3552-9.

5. Strauss GM, Herndon JE II, Maddaus MA, Johnstone DW, Johnson EA, Harpole DH, et al. Adjuvant paclitaxel plus carboplatin compared with observation in stage IB non-small-cell lung cancer: CALGB 9633 with the cancer and 
leukemia group B, radiation therapy oncology group, and north central cancer treatment group study groups. J Clin Oncol. 2008;26:5043-51.

6. Higgins KA, Chino JP, Ready N, D’Amico TA, Berry MF, Sporn T, et al. Lymphovascular invasion in non-small-cell lung cancer: implications for staging and adjuvant therapy. J Thorac Oncol. 2012;7:1141-7.

7. Yilmaz A, Duyar SS, Cakir E, Aydin E, Demirag F, Karakaya J, et al. Clinical impact of visceral pleural, lymphovascular and perineural invasion in completely resected non-small cell lung cancer. Eur J Cardiothorac Surg. 2011;40:664-70.

8. Hanagiri T, Takenaka M, Oka S, Shigematsu Y, Nagata Y, Shimokawa H, et al. Prognostic significance of lymphovascular invasion for patients with stage I non-small cell lung cancer. Eur Surg Res. 2011;47:211-7.

9. Yanagawa N, Shiono S, Abiko M, Ogata SY, Sato T, Tamura G. Prognostic impact and initial recurrence site of lymphovascular and visceral pleural invasion in surgically resected stage I non-small-cell lung carcinoma. Eur J Cardiothorac Surg. 2013;44:e200-6.

10. Chen YY, Huang TW, Tsai WC, Lin LF, Cheng JB, Chang H, et al. Risk factors of postoperative recurrences in patients with clinical stage I NSCLC. World J Surg Oncol. 2014;12:10.

11. Chen YY, Huang TW, Tsai WC, Lin LF, Cheng JB, Lee SC, et al. Lymphovascular space invasion and tumor differentiation are predictors for postoperative recurrence in patients with pathological stage I nonsmall cell lung cancer. $J$ Chin Med Assoc. 2014;77:416-21.

12. Kinoshita T, Ohtsuka T, Yotsukura M, Asakura K, Goto T, Kamiyama I, et al. Prognostic impact of preoperative tumor marker levels and lymphovascular invasion in pathological stage I adenocarcinoma and squamous cell carcinoma of the lung. J Thorac Oncol. 2015;10:619-28.

13. Sedlis A, Bundy BN, Rotman MZ, Lentz SS, Muderspach LI, Zaino RJ. A randomized trial of pelvic radiation therapy versus no further therapy in selected patients with stage IB carcinoma of the cervix after radical hysterectomy and pelvic lymphadenectomy: a gynecologic oncology group study. Gynecol Oncol. 1999;73:177-83.

14. Keys HM, Roberts JA, Brunetto VL, Zaino RJ, Spirtos NM, Bloss JD, et al. A phase III trial of surgery with or without adjunctive external pelvic radiation therapy in intermediate risk endometrial adenocarcinoma: a gynecologic oncology group study. Gynecol Oncol. 2004;92:744-51.

15. Heaps JM, Fu YS, Montz FJ, Hacker NF, Berek JS. Surgical-pathologic variables predictive of local recurrence in squamous cell carcinoma of the vulva. Gynecol Oncol. 1990;38:309-14.

16. Huang TY, Hsu LP, Wen YH, Huang TT, Chou YF, Lee CF, et al. Predictors of locoregional recurrence in early stage oral cavity cancer with free surgical margins. Oral Oncol. 2010;46:49-55.

17. Lim E, Baldwin D, Beckles M, Duffy J, Entwisle J, Faivre-Finn C, et al. Guidelines on the radical management of patients with lung cancer. Thorax. 2010; 65(Suppl 3):iii1-27.

18. Goldstraw P, Crowley J, Chansky K, Giroux DJ, Groome PA, Rami-Porta R, et al. The IASLC lung cancer staging project: proposals for the revision of the TNM stage groupings in the forthcoming (seventh) edition of the TNM classification of malignant tumors. J Thorac Oncol. 2007;2:706-14.

19. Moon Y, Lee KY, Park JK. Prognosis after sublobar resection of small-sized nonsmall cell lung cancer with visceral pleural or lymphovascular invasion. World $J$ Surg. 2017;41:2769-77.

20. Al-Alao BS, Gately K, Nicholson S, McGovern E, Young VK, O’Byrne KJ. Prognostic impact of vascular and lymphovascular invasion in early lung cancer. Asian Cardiovasc Thorac Ann. 2014;22:55-64.

21. Tao H, Hayashi T, Sano F, Takahagi A, Tanaka T, Matsuda E, et al. Prognostic impact of lymphovascular invasion compared with that of visceral pleural invasion in patients with pN0 non-small-cell lung cancer and a tumor diameter of 2 cm or smaller. J Surg Res. 2013;185:250-4.

22. Maeda R, Yoshida J, Ishii G, Hishida T, Nishimura M, Nagai K. Influence of cigarette smoking on survival and tumor invasiveness in clinical stage IA lung adenocarcinoma. Ann Thorac Surg. 2012;93:1626-32.

23. Araki K, Adachi Y, Metsugi H, Tokushima T. Prognostic implication of lymphatic vessel invasion in stage IB (pT2aNOM0). Gen Thorac Cardiovasc Surg. 2011;59:605-8.
24. Funai K, Sugimura H, Morita T, Shundo Y, Shimizu K, Shiiya N. Lymphatic vessel invasion is a significant prognostic indicator in stage IA lung adenocarcinoma. Ann Surg Oncol. 2011;18:2968-72.

25. Sakai Y, Ohbayashi C, Kanomata N, Kajimoto K, Sakuma T, Maniwa Y, et al Significance of microscopic invasion into hilar peribronchovascular soft tissue in resection specimens of primary non-small cell lung cancer. Lung Cancer. 2011;73:89-95.

26. Harada M, Hato T, Horio H. Intratumoral lymphatic vessel involvement is an invasive indicator of completely resected pathologic stage I non-small cell lung cancer. J Thorac Oncol. 2011;6:48-54.

27. Maeda R, Ishii G, Yoshida J, Hishida T, Nishimura M, Nagai K. Influence of cigarette smoking on histological subtypes of stage I lung adenocarcinoma. J Thorac Oncol. 2011;6:743-50.

28. Shimada Y, Ishii G, Hishida T, Yoshida J, Nishimura M, Nagai K. Extratumoral vascular invasion is a significant prognostic indicator and a predicting factor of distant metastasis in non-small cell lung cancer. J Thorac Oncol. 2010;5:970-5.

29. Kawachi R, Tsukada H, Nakazato Y, Takei H, Furuyashiki G, Koshi-ishi Y, et al. Early recurrence after surgical resection in patients with pathological stage I nonsmall cell lung cancer. Thorac Cardiovasc Surg. 2009;57:472-5.

30. Kawachi R, Nakazato Y, Masui K, Takei H, Koshi-ishi Y, Goya T. Clinical significance of pleural lavage cytology for non-small cell lung cancer: is surgical resection valid for patients with positive pleural lavage cytology? Interact Cardiovasc Thorac Surg. 2009;9:265-8.

31. Sun JG, Wang Y, Chen ZT, Zhuo WL, Zhu B, Liao RX, et al. Detection of lymphangiogenesis in non-small cell lung cancer and its prognostic value. J Exp Clin Cancer Res. 2009;28:21.

32. Hashizume S, Nagayasu T, Hayashi T, Hidaka S, Tsuchiya T, Tagawa T, et al. Accuracy and prognostic impact of a vessel invasion grading system for stage IA non-small cell lung cancer. Lung Cancer. 2009;65:363-70.

33. Higashiyama M, Oda K, Okami J, Maeda J, Kodama K, Takenaka A, et al. Prognostic value of intraoperative pleural lavage cytology for lung cancer. Eur J Cardiothorac Surg. 2009;35:337-42.

34. Bodendorf MO, Haas V, Laberke HG, Blumenstock G, Wex P, Graeter T. Prognostic value and therapeutic consequences of vascular invasion in non-small cell lung carcinoma. Lung Cancer. 2009;64:71-8.

35. Matsuguma H, Nakahara R, Igarashi S, Ishikawa Y, Suzuki H, Miyazawa N, et al Pathologic stage I non-small cell lung cancer with high levels of preoperative serum carcinoembryonic antigen: clinicopathologic characteristics and prognosis. J Thorac Cardiovasc Surg. 2008;135:44-9.

36. Hanahan D, Weinberg RA. Hallmarks of cancer: the next generation. Cell. 2011; 144:646-74.

37. Wang J, Wang B, Zhao W, Guo Y, Chen H, Chu H, et al. Clinical significance and role of lymphatic vessel invasion as a major prognostic implication in non-small cell lung cancer: a meta-analysis. PLoS One. 2012;7:e52704.

38. Schuchert MJ, Schumacher L, Kilic A, Close J, Landreneau JR, Pennathur A, et al. Impact of angiolymphatic and pleural invasion on surgical outcomes for stage I non-small cell lung cancer. Ann Thorac Surg. 2011; 91:1059-65.

39. Arigami T, Natsugoe S, Uenosono Y, Arima H, Mataki Y, Ehi K, et al. Lymphatic invasion using D2-40 monoclonal antibody and its relationship to lymph node micrometastasis in pNO gastric cancer. Br J Cancer. 2005; 93:688-93.

40. Kaiserling E. Immunohistochemical identification of lymph vessels with D2-40 in diagnostic pathology. Pathologe. 2004;25:362-74.

41. Kahn HJ, Marks A. A new monoclonal antibody, D2-40, for detection of lymphatic invasion in primary tumors. Lab Invest. 2002;82:1255-7.

42. Ordonez NG. D2-40 and podoplanin are highly specific and sensitive immunohistochemical markers of epithelioid malignant mesothelioma. Hum Pathol. 2005;36:372-80.

Key Words: lymphovascular invasion, non-small cell lung cancer, overall survival 